the early stage and the course which the two diseases run are so entirely different that a diagnosis is easily made; moreover, in cases that arise in the course of other diseases, in addition to the differences just stated, there is an absence of the throat lesion and that characteristic condition of the tongue-signs that should guide us almost more than any other in determining an attack of scarlet fever. There is no doubt but that the eruption, when fully developed, resembling so closely as it does the intense or blotched rashes often seen in scarlet fever, and the subsequent desquamation c.)mbine to render a correct diagnosis difficult if the primary syurptoms have not been carefully observed. It is also confounded with measles, rötheln, eruptions produced by drugs, urticaria, erysipelas, \&c., and although the rash sometimes resembles that of measles and rötheln, by careful attention to the invasion, the early distribution of the eruption, and the absence of the catarrhal symptoms found in these diseasesmore especially measles-it is always easy to arrive at a correct diagnosis. In the other conditions named the differences are so many and so manifest that a diagnosis should present no difficulty,

Birmingham.

\section{TWO CASES OF RETRO-PHARYNGEAL ABSCESS IN INFANTS.}

\section{BY W. T. BROOK, F.R.C.S. ENG.}

rist notes of the following two cases may be of interest, as they not only closely resemble the cases which form the basis of Mr. Bilton Pollard's paper on the above subject in FuE LANCET of Feb. 13th, but also bear out his remarks as to their etiology and treatment. I believe $I$ am right in saying that these were the only two cases of the kind which presented themselves at the Hospital for Sick Children, Great Ormond-street, during the fourteen months that I was house surgeon there.

The first case-M. G-, a female child aged one year and seven months-was brought to the hospital on Oct. 13th, 1890, suffering from difficulty of breathing and swallowing and a "lump" in the neck. "The history given was that a swelling sad been noticed in the neck a fortnight previously, which gradually increased in size. Breathing and swallowing became difficult and continued to get worse until admission. She had had whooping-cough the previous February, since which she had suffered from discharge from the nose. There had been no pain or stiffness in the neck before the swelling was noticed. Four months previously she fell from a chair, striking her head. On examination, in the right side of the nock was a diffuse non-fuctuating swelling, situated behind but extending under the sterno-mastoid and pushing it and the carotids forwards, with a more defined lump in the centre, apparently a gland rendered promirent by the subjacent swelling. The right tonsil was seen to be pushed towards and beyond the mid line, obscuring the view of the parts beyond. Chloroform was given, with a view to making a more thorough examination and doing what might be required. A gag was introduced in to the mouth for the more complete examination of the pharynx, when the breathing suddenly stopped, the child kecoming cyanosed. The trachea was immediately opened an $x$ the patient brought quickly round by artificial respiration. With the tube in the trachea, the swelling in the pharynx could be examined at leisure. It extended from the right twnsil across the back of the pharynx nearly to the left. Its upper limit was at the base of the skull, its lower limit below the level of the glotitis. It was so tense that fluctuation could barely be made out. Although, had the abscess been opened from the pharynx, the presence of the tracheotomy tube would have removed the danger of asphyxin, the impossibility of keeping the carity aseptic under these conditions led me to prefer to drain it from the neck. Accordingly a small incision was made along the posterior border of the sternomastoid and the dissection continued beneath it until a wave $o f$ impulse could be distinctly felt between a finger at the buttom of the hole thus made and another on the swelling in the pharynx. With a blunt director and a pair of dressing forceps the akscess was then speedily emptied, the swelling in the pharynx at once subsiding. No bare bone could be felt by the finger introduced into the abscess cavity. The latter was washed out with perchloride of mercury 1 in 2000 ), a drainage tube introdnced, and the incision closed at the ends with sutures. The tracheotomy tube was remored and the wound sutured also. "The breathing was now in every respect normal. The temperature, which on admission was $98.8^{\circ}$, on three occasions within the next few dips reached $100^{\circ} \mathrm{F}$. With a view to keeping the injured parts at rest the patient was fed for the first twenty-four hours rectum. The discharge from the wound in the neck was slight and the tube was gradually shortened and remored entirely on the seventh day. The tracheotomy wound did not heal by first intention, but gave no trouble. The child was discharged on Nov. 3rd, with both wounds healed and no sign of spinal caries.

The second case was that of $\mathrm{W} . \mathrm{L}-$, a male child aged six months. He had been ill a fortnight with a "swelling in the neck and wheezing." There had been a slight discharge from the nose during the previous week, but not any discharge from the ear. The history did not suggest spinal caries or syphilis, but there was a history of phthisis on the father's side. On admission on Dec. 23rd, 1890, the notes describe him as an emaciated and rickety child, breathing with some effort. The crying was feeble. There was retraction of the lower ribs and to a less degree above the clavicles. In the neck on the left side was a fluctuating swelling beneath the sterno-mastoid. In the upper part of the pharynx, on the left side, was a fluctuating swelling extending up behind the soft palate and across the middle line. As the sterno-mastoid muscle seemed unusually wide and thin and pus was evidently immediately beneath it, I opened the abscess by a small vertical incision through the muscle. The finger introduced through the opening passed behind the carotid sheath and the pharynx beyond the middle line, and could feel the base of th skull above. There was no bare bone to be felt. An inch and a half of small drainage-tube was inserted and the cavity washed out with perchloride of mercury (1 in 2000). Immediately after opening the abscess breathing was relieved and the cry became stronger. In three days' time the tube $\max$ removed and the child was discharged on Jan. 4th, 1891

In both these cases there was a history of irritation and inflammation of the nasal or naso-pharyngeal mucous mem. branes, and in neither was the abscess associated with cerrical caries or of tonsillar origin. The analogy between this form of retro-pharyngeal abscess and subacute or chronic ischio-rectal abscess so common in feeble and cachectic subjects is very striking. Both occur in weakly and debilitated individuals and seem to result from apparently slight irritation of the adjacent mucous membranes, and in each case, too, it is in the submucous tissue that the suppuration occurs and not in glands (or at all erents those demonstrated in naked-eyo anatomy) which drain the corresponding area of mucous membrane.

The above cases were under the care of Mr. Morgan and Mr. Owen respectively, to whom I am indebted for permission to publish them.

Swansea, S. Wales.

\section{ANGEIO-LEUCITIS AND DEATH FROM INFECTION BY MICRO-ORGANISMS DERIVED FROM THE ADHESIVE SURFACE OF BUNION PLASTER.}

BY A. S. MYRTLE, M.D. EDIN.

Mns. - aged forty-nine, enjoyed good health and le an active out-door life since childhood; regular in all func tions; she had seven children, the youngest being aged thirteen. About the 16th of May, to protect a bunion 01 the right foot, she applied a felt plaster; this was wor for a fortnight, when the bunion got red and painfu and a small ulcer was found on the great toe, where th hardened gelatine had worked its way through the skin The sore was a quarter by one-eighth of an inch. Abou the end of May she felt "seedy," listless and nervous; be appetite had failed, and her nights were disturbed. Sh then consulted me. I found her, as I thought, very muc below par; she was worrying herself about going to th Continent. I advised her to remain at home and prescribed tonic, and, as the bunion was inflamed and painful, ordere lead and opium lotion. The ulcer, which looked sluggis and void of healthy granulations, I covered with iodofor and salicylic cotton-wool, and ordered the foot to be kept rest. 
On June 6th my son saw her. She complained of pain in the centre of the right patella, slight pain and swelling on the inside of the left wrist, and pain in the palmar aspect, first phalanx, of the forefinger of the left hand. She looked and felt ill, but there was no constitutional disturbance and the temperature, pulse and functions were normal. He thought the symptoms indicated either rheumatism or gout as their cause. He saw her again on the 7 th ; the symptomas were then unchanged. On the 8th I visited her and could discover nothing fresh. I inquired about the sanitary condition of her surroundings, and these were thought to be perfect, but she admitted she had felt that the stable in which some pet ponies were kept was in a most vile state and that the stench, when she had been there for ten minutes, almost made her sick. On the 12th she came to Harrogate. She was much exhausted by the long drive and complained of severe pain in various groups of muscles, in the calves, the soles of the feet, the hips and intercostal muscles on the right side. Pulse 72; temperature $98.5^{\circ}$. Any attempt at movement aggravated pain; and on the 14th this was so great that she took to her bed. On closer examination I found the lower extremities much wasted. I could almost wrap the skin of the calf round the shin-bone. This I attributed to trophic nerve disturbance. She was able to take food well. As the ulcer was still unhealed I applied creolin lotion. On the 17th the ulcer had healed, but the nurse called my attention to a slight redness on the left great toe and the dorsum of the foot; this was clearly erysipelatous; and on examining the leg I found it greatly swollen, the skin cool but tense, the swelling, elastic and involving the whole leg and thigh, did not pit on pressure. I told the patient she had what is usually called a white leg, and that I had never met with such a case.18th : Pains more severe than ever.-19th : Much the same.20th: Slight erysipelas on the back of the left thigh; pulse and temperature normal ; taking plenty of nourishment, with brandy and champagme.-21st: Patient worse. I called Dr. Eddison of Leeds in consultation, but told him nothing, as I wished to have his own opinion unbiased by mine. He examined her most carefully, got her out of bed, but as soon as her feet tonched the ground the pain was so severe we had to put her back. Dr. Eddison admitted he had never seen or read of such a case. He saw her again on the 22 nd, when she was in much the same condition. As to treatment, excepting morphia lypodermically, nothing proved of the slightest use. - 30th: The upper and posterior left thigh looked as if pus was forming, the erysipelas had extended, and I put her on solution of perchloride of iron, chlorate of potash and boric acid, and wired for Mr. Jessop, as I wished for a surgical opinion. At 4.30 he saw her, pronunced the case to be one of inflammation of the lymphatics, and thought it most critical. - July 1st: All pain gone from the left $\operatorname{limb}$; also erysipelas abated; but pain and swelling in the right thigh lad developed; pulse 84 ; temperature $100^{\circ}$. I doubled the amount of brandy and continued the iron mixture and morphia.-2nd: Mr. Jessop came again ; ererytling seemed to be going on as favourably as we could expect, so much so that he proposed to meet me on the 4:h. -3rd: She had passed a restless night and rambled slightly; still she took plenty of nourishment; pulse 90 ; temperature $100 \cdot 3^{\circ}$. At 8 P.M. I found her in the same state, and administered the usual dose of morphia; at 10 she took soup and brandy. At $12 \mathrm{I}$ was called and found her dying. She died ten minutes after my arrival.

What puzzled me was the severity of the pain, the suddenness of its attacks and the total absence of heat, swelling, inflammation or constitutional disturbance. I looked on it as acute neuralgia. Until June 17th there was no local change, and then the mischief showed itself not in the leg where the ulcer had been but in the other. Before coming to any conclusion as to the cause of death I had all the drains of the dwelling-house, out-houses and stables thoroughly examined by Mr. Slater, sanitary engineer, Leeds. He sent me a full report, and added: "In conclusion there appears to be no serious sanitary defect in the system of drainage," which is borne out by the fact that all the inmates of a very large establishment and even the stablemen, who spent hours in the ponies' stable, were in good health. Bloodpoisoning we had here without doubt, and I am driven to the conclusion that some pathogeni micro-organisms buried in the gelatine took possession of the denuded surface and so infected $m y$ patient. Considering that all sorts of animal refuse are made use of in the manufacture of glues \&c.-diseased hoofs, horns, parings of hides \&c.-- the wonder is that more cases of infection by such germs have not been met with, and if I am right in my view, a Government inspector should be appointed, so as to prevent the utilisation of diseased animal refuse in the production of articles of commerce which must be brought into contact not only with the skins, but with the lips and mucous memkranes of all classes of the community.

Harrogate.

\section{THE PLACE OF ANTHROPOLOGY IN MEDICAL EDUCATION.}

\section{BY HAVELOCK ELLIS, L.S.A.}

VIRcHow, who adds to his other claims to farve that of being the first of living anthropologists, has recently confessed that his attention was directed to the science of anthropology by the difficulties he encountered in the study of the insane. Charcot, again, frequently impresses on his pupils the importance of studying the healthy nude, and of an acquaintance with anthropometric canons, as an aid to the diagnosis of abnormal conditions. These utterances of two of the most honoured of our teachers in very different fiejds suggest that there is a defect in our medical courses, as they exist at present in England, which demands, at the least, some consideration. As evidence of the close relationship between anthropology and medical practice, it is enough to mention that in spite of the difficulties we at present place in the way, with a few exceptions (in which zoology alone led up to anthropology), the chiet anthropologists of the last balf century have been medical men-in not a few cascs very distinguished in the profession; at the least, they I: ve started as students of medicine. It is sufficient to mentior in France Broca, Topinard, Lacassagne, Manourvier, Collignon and Letourneau ; in Germany, around and below Virchow, Ranke, Schaefthausen, Ploss, Bartels and many others; in Italy, Mantegazza, Lombroso, Sergi ; in our own country, Galton, Bedcloe, Sir Wm. Turner, Flower and Garson, while to a somewhat earlier period belong the great names of Prichard and Thurnam. While every medical man wonld find a slight acquaintance with anthropology some help in practice, there are certain branches of practice in which some knowledge of anthropology is of especial assistance ; for example, practice abroad and asylum practice. No country sends out so large a body of medical men into all parts of the world, but the amount of scientific work done among the races of our great empire by these men is so small that it is scarcely perceptible. French medical men have done far more for their few colonies, and the medico-lesal and anthropological studies which have come from the Lyons school, under the inspiring influence of Lacassagne, are especially worthy of honour.

What is true generally of the English medical man abroad is equally true of the English alienist at home, and must be so, since the study of anthropology is largely the study of the manilestations of the brain and nervous systems. In the practical treatment of the insane England stands before every other country; in the scientific study of the insane no leading country is so backward. Elsewhere the exact study of madness is making rapid progress ; it is beginning to be recognised that the great truth that knowledge means measurement (scire est mensurare) fully applies to the brain and nervous system. But in this country the rule-of thumb method still reions nearly everywhere. In the hands of a master in psychiatry the rule-of-thumb method more often than not leads to perfectly reliable conclusions as to the mental status and condition of the subject before him, bnt it has two obvious disadvantages: it can only be trusted in the hands of a master; while even a master's mere impressions, however trustworthy, add nothing to the common stock of scientific knowledge. In actual practice, with our present knowledge of neurology, it is becoming a great advantage to the alienist to be able to demonstrate that his subject is twisted in anatomical structure and perverted in physiological action; while, so far as science is concerned, in the end it is only accurate obserpation that counts. 